\title{
Planeación didáctica en educación secundaria: un avance hacia la socioformación
}

Maribel Brito-Lara mabila68@hotmail.com Secretaría de Educación de Guanajuato, Escuela Normal Superior Oficial de Guanajuato, México https://orcid.org/0000-0002-2800-3436

José LÓPEZ-LOYA jlloya@ymail.com

Servicios Educativos del Estado de Chihuahua, México https://orcid.org/0000-0003-0001-5766

Haydé́ PARRA-Acosta hparra@uach.mx Universidad Autónoma de Chinuahua, Escuela de Medicina, México https://orcid.org/0000-0003-1720-7182

\section{Resumen}

Se presenta un estudio cuantitativo realizado en el ciclo escolar 2015-2016, orientado a identificar las finalidades, enfoques y aspectos que toman en cuenta los profesores de secundaria para elaborar sus planeaciones didácticas. Participaron 433 docentes mexicanos. Los resultados muestran preponderancia de finalidades pedagógicas, si bien las evaluativas tienen importante ponderación; aun cuando el enfoque tradicional está considerablemente presente, se identifica de alguna forma el socioformativo. En este sentido, se concluye que las prácticas tradicionales no se alejan de las escuelas aun cuando hay argumentos en el discurso docente en los aspectos que utilizan en el diseño de la planeación didáctica.

\section{Palabras clave}

Plan de clase; objetivo educacional; método pedagógico

\begin{abstract}
This paper reports a quantitative study carried out during the school cycle 2015-2016, which sought to identify the purposes, approaches and aspects considered by the secondary education teachers when preparing their didactic plans. In total 433 Mexican teachers took part in the study. The results indicate a prevalence of the pedagogical purposes, notwithstanding the evaluations have a significant weighting. Although the traditional approach is considerably present, the social formation element is somehow identified. This way, a conclusion is drawn that the traditional practices are not getting away from the schools, even though some aspects of the teaching discourse have arguments based on the didactic planning design.
\end{abstract}

\section{Keywords}

Lesson plans; educational objectives; teaching methods

Para citar este artículo / To cite this article

Brito-Lara, M.; López-Loya, J. \& Parra-Acosta, H. (2019). Planeación didáctica en educación secundaria: un avance hacia la socioformación. magis, Revista Internacional de Investigación en Educación, 11 (23), 55-74. doi: 10.11144/Javeriana.m11-23.pdes 


\section{Introducción}

La planeación didáctica es una tarea inherente al trabajo profesional docente que permite organizar y vincular cronológica, espacial, pedagógica y técnicamente, las actividades y recursos necesarios para lograr los aprendizajes previstos (Melitón García \& Valencia Martínez, 2014; Tenutto, Brutti \& Algarañá, 2010). En los últimos tiempos ha estado sujeta a debates $y$, por tanto, a encuentros y desencuentros en torno a su sentido y utilidad; asimismo en cuanto a enfoques, aspectos e, incluso, estructura.

Con base en lineamientos normativos, esta herramienta organizativa de la enseñanza es uno de los cuatro aspectos esenciales para evaluar la idoneidad de conocimientos y capacidades de los docentes de educación básica'. Expresamente se demanda elaborar una planeación didáctica argumentada como muestra del ejercicio que se hace en la práctica cotidiana (SEP, 2015a).

En la literatura académica no hay información sobre la planeación didáctica argumentada, tampoco se han realizado investigaciones que precisen de forma objetiva en qué medida la planeación responde a las necesidades educativas de los estudiantes de secundaria y contribuye al desarrollo de lo propuesto en el Plan de Estudios de Educación Básica (SEP, 2011a); si bien encontramos estudios que dan cuenta del sentido, importancia o impacto de la planeación didáctica en educación básica, los cuales se refieren enseguida:

En Argentina, Andrea Alliaud y Lea Vezub (2015) realizaron un estudio cualitativo - con participación de docentes (de primaria y secundaria) y formadores - para conocer acerca de los saberes necesarios en los profesores para enseñar en la actualidad. Encontraron que la planeación didáctica es uno de esos saberes. Si bien los formadores le otorgan una "importancia crucial" a esta, para los profesores es importante pero no en tal dimensión y consideran que, en esta tarea preactiva de la enseñanza, la selección y el grado de adecuación al grupo son dos aspectos clave.

En Venezuela, Ninoska Viloria y Gloribet Godoy (2010) realizaron un estudio cuasi experimental con estudiantes de sexto grado en un bloque de la asignatura de matemáticas. Concluyeron que al planear (y aplicar) estrategias didácticas de acuerdo con las necesidades e intereses de los estudiantes, se logran mejores procesos y resultados educativos.

En México, Fernando Dueñez Serrano y Arturo Barraza Macías (2015), como parte de un estudio etnográfico para identificar la relación entre la formación inicial de profesores de secundaria y su quehacer docente encontraron que, ante la diversidad de formación inicial de los profesores (en muchos casos ajena al ámbito educativo), se propician situaciones desfavorables como el hecho de que no elaboren o no pongan en práctica la planeación didáctica; o bien que la elaboración de esta sea más bien para cumplir con el requisito administrativo. Por otra parte, Miguel Navarro Rodríguez y María del Consuelo Telles Contreras (2013) llevaron a cabo un estudio cuantitativo para caracterizar el proceso de planeación didáctica por competencias de profesores de primaria y correlacionarlo con los logros de aprendizaje. Entre los hallazgos destacan que tal planeación es valorada (sobre todo por docentes nóveles, con mayor nivel de estudios y formación continua específica en tal ámbito) como altamente favorable en su papel de herramienta didáctica para el desarrollo de la práctica educativa y el logro de aprendizajes; se perciben cambios en este tipo de planeación en el orden de las estrategias, los aprendizajes esperados, la secuencia didáctica,

1 En México, la educación básica está integrada por tres niveles: preescolar, primaria y secundaria. 
los materiales y recursos, el pensamiento crítico, la reflexión de los valores, etc. y que hay una asociación — ligera - entre la presentación de mejores índices de rendimiento escolar y la planeación didáctica.

Por lo anterior se desarrolló esta investigación, con la cual se pretende identificar las finalidades, enfoques y aspectos que toman en cuenta los profesores de educación secundaria al elaborar sus planeaciones didácticas; conocer en qué medida usan la socioformación dentro del diseño de estas y; saber si reciben asesoría para el desarrollo de tal tarea.

\section{Referentes conceptuales}

En el contexto educativo, la planeación didáctica tiene diversas connotaciones. Esta diversidad implica un soporte metodológico y por supuesto, un determinado enfoque pedagógico que la sustenta.

La enseñanza tradicional no solo se apoya en la enseñanza enciclopedista, academicista, conductista, tecnología educativa (Alonso Tejeda, 2009; Flórez Petour, s.f.; Ribes-Iñesta, 2008) u otros, sino que implica además todas aquellas posturas que centran su atención en los contenidos, objetivos o programas de estudio. En ese enfoque, la enseñanza es lo más importante y, por tanto, el maestro es la figura central; los libros de texto son fundamentales en la tarea docente; el conocimiento estático es un elemento principal del proceso didáctico; las técnicas de enseñanza van encaminadas hacia la adquisición de conceptos; y la evaluación se centra en los resultados o productos de aprendizaje. Como aprender equivale a adquirir y reproducir lo que el docente transmite a los alumnos, con base en una prescripción o en su defecto en una decisión personal, la planeación didáctica —en todo caso - se reduce a la programación o dosificación de tiempos para abordar los contenidos y lograr los objetivos previstos en el programa curricular, esto es, se centra en los fines normativos de la planeación.

El enfoque vigente considera al alumno como centro del proceso educativo. De acuerdo con esto, la enseñanza tiene como objetivo ayudar a los alumnos a desarrollar su potencial cognitivo: los recursos intelectuales, personales y sociales que les permitan participar como ciudadanos activos (SEP, 2017). Con ello se propicia el desarrollo de una serie de competencias básicas relacionadas con los cuatro pilares de la educación: aprender a ser, aprender a saber, aprender a hacer y aprender a vivir juntos (Moya López, 2013). Estas competencias implican un entramado complejo de conocimientos, habilidades, actitudes y motivación que cada individuo moviliza o pone en juego para hacer frente a las exigencias que demanda una situación específica en un contexto determinado (Tacca Huamán, 2011). Lo anterior requiere un cambio en las prácticas docentes. Más que un instructor, el docente debe convertirse en un mediador que genere ambientes de formación flexibles, dinámicos, retadores y estimulantes centrados en la resolución de problemas del contexto real, para que los alumnos puedan lograr la formación integral y desarrollar las competencias con sustentabilidad (Parra Acosta, Tobón \& López Loya, 2015). Por tanto, corresponde a los profesores generar situaciones — reales o simuladas-, lo más auténticas y holistas posible (Díaz Barriga Arceo, 2006), graduar la dificultad de las tareas y proporcionar a los estudiantes los apoyos necesarios para afrontarlas (Díaz Barriga Arceo \& Hernández Rojas, 2010), considerando siempre la diversidad de los educandos y las condiciones del entorno; de ahí el sentido de la planeación didáctica cuyo énfasis se remite a sus fines pedagógicos. La evaluación es formativa y valora el desempeño de los alumnos ante las tareas o desempeños propuestos, con base en evidencias concretas.

El constructivismo es el marco de referencia para la reflexión sobre qué y cómo se construye, quién y con quién se construye el conocimiento (Serrano GonzálezTejero \& Pons Parra, 2011). También se lo reconoce como el nicho teórico en el que se encuentran algunas de las estrategias propuestas por el modelo educativo 2017 (SEP, 2017) consideradas en las secuencias didácticas, como el aprendizaje situado, el aprendizaje distribuido y el aprendizaje colaborativo (Coll Salvador, Bustos Sánchez \& Engel, 2008) que propician que los niños y jóvenes aprendan a aprender en la interacción con otros y con el medio. Referir al aprendizaje implica analizar su perspectiva epistemológica, es decir, la génesis de lo que se conoce. Juan Manuel Serrano González-Tejero y Rosa María Pons Parra (2011) hacen referencia a cuatro tipos de constructivismo en el ámbito educativo: 1) Constructivismo radical, donde solo cuenta el sujeto que aprende (inter), el elemento social es irrelevante; 2) Constructivismo cognitivo (intra-inter), el elemento social es coadyuvante pero no indispensable; 3) Constructivismo social, el componente social es condición necesaria (intra-inter) y; 4) Constructivismo sociocultural, el elemento social es necesario pero no suficiente (intra-inter) se considera que la persona construye significados actuando en un entorno estructurado e interactuando con otras personas de forma intencional. Es decir, los estudiantes desarrollan competencias al interactuar con las personas pero además al resolver problemas del contexto en ambientes reales. De ahí que el constructivismo desde la perspectiva sociocultural sea fundamento de la socioformación.

La socioformación da centralidad a la formación integral de los educandos. Los procesos educativos se orientan a que los estudiantes desarrollen competencias para desenvolverse a lo largo de la vida; es decir, lleven a cabo actuaciones integrales para identificar, 
analizar y resolver problemas del contexto (Tobón Tobón, Pimienta Prieto \& García Fraile, 2010). En la planeación didáctica se articulan actividades de aprendizaje y evaluación para el logro de determinadas metas educativas, siendo necesaria la mediación docente. Evaluar equivale a valorar el proceso mismo del desarrollo de competencias, con base en evidencias; de modo que cada estudiante se dé cuenta de cómo va en su formación académica y, en tal sentido, se le brinden apoyos para la mejora.

La socioformación responde a las necesidades de la sociedad del conocimiento, en la cual se requiere afrontar la resolución de los problemas en el contexto local con una visión global, a partir del empleo de las tecnologías de la información y la comunicación para la gestión del conocimiento en diferentes fuentes con sentido crítico (Tobón, González, Nambo \& Vázquez, 2015), en procura de "formar personas con un sólido proyecto ético de vida, emprendimiento, trabajo colaborativo, co-creación del conocimiento y metacognición para resolver problemas en contextos cambiantes y complejos" (Sergio Tobón, 2014, en Parra Acosta, Tobón \& López Loya, 2015, p. 2); asimismo, fortalecer la construcción y reconstrucción del tejido social (Tobón, 2013), lo cual deja de lado el enfoque funcionalista de las competencias que ha predominado. Así, el enfoque socioformativo:

1. No solo afronta retos del contexto presente sino futuros.

2. Enfatiza la formación del compromiso ético ante uno mismo, la especie humana, las otras especies, el ambiente ecológico, la tierra y el cosmos.

3. Sigue los principios del pensamiento sistémico complejo: inter y transdisciplinariedad, multiplicidad de relaciones en contexto, los cambios constantes en todas las áreas y los procesos de cambios e incertidumbres (Tobón Tobón, Pimienta Prieto \& García Fraile, 2010).

Ahora bien, el Plan de Estudios de Educación Básica se plantea con base en lo que se ha caracterizado como enfoque vigente. Se orienta a que los educandos desarrollen competencias para la vida y logren el perfil de egreso; de modo que sean capaces de responder a los requerimientos sociales en los cuales el conocimiento es fuente principal para la creación de valor, la globalidad e interdependencia son condiciones para el desarrollo y, por tanto, las relaciones en un marco de pluralidad y democracia son indispensables (SEP, 2011a). Para lograr tales finalidades educativas, corresponde al docente, entre otras acciones o tareas, planificar la enseñanza para favorecer los aprendizajes. En el citado currículo se prescribe para qué enseñar (propósitos), qué enseñar (asignaturas y contenidos), cuándo enseñar (orden y secuencia de contenidos y propósitos), cómo enseñar (sugerencias didáctico-metodológicas) y, qué y cómo evaluar (criterios y procedimientos); pero para la concreción en el aula es necesario tener en cuenta la adaptación a las características del contexto en que se llevan a cabo los procesos de enseñanza y de aprendizaje (SEP, 2012; Irene Solís citada en Guzmán, 2013), de modo que se logre lo esperado, tal adaptación es la razón de ser de la planeación didáctica.

Con base en las demandas del citado plan de estudios y para evaluar el desempeño profesional en torno a ellas, se solicita a los profesores la elaboración de una planeación didáctica argumentada, cuyo fin es evaluativo puesto que se centra en los intereses del docente por obtener buenos resultados en su proceso de evaluación. Esa planeación deberá contener los siguientes rubros (SEP, 2015c):

- Contexto interno y externo de la escuela

- Diagnóstico del grupo

- Elaboración del plan de clase

- Estrategias de intervención elegidas

- Estrategia de evaluación

Tras la evidencia (planeación didáctica) se demanda que los docentes, por medio de una plataforma digital y con base en preguntas guías allí señaladas, expliquen y argumenten en torno a las estrategias para la intervención docente planteadas.

No obstante, el diseño y elaboración de la planeación didáctica ha tomado importancia a raíz de la evaluación del desempeño docente, entonces, el problema no solo es ¿qué elementos y estructura utilizan los docentes para diseñar este documento en función de la evaluación del desempeño?, sino ¿cuáles son los aspectos y estructura que el docente considera para elaborar la planeación que utiliza de manera cotidiana en las aulas?

\section{Metodología}

\section{Diseño de la investigación}

Se trata de un estudio con enfoque cuantitativo y diseño transversal, el que participaron 433 profesores de educación secundaria: 337 de secundarias generales del Estado de Chihuahua y 96 de telesecundarias de tres localidades del Estado de Guanajuato. Es exploratorio, pues no se cuenta con investigaciones previas sobre el tema. Es descriptivo, ya que se busca revisar las características de las variables en las poblaciones y muestra de estudio, esto es, caracterizar la planeación de clases en sus diferentes finalidades, enfoques y aspectos. 


\section{Definición de variables}

En función de los objetivos de investigación, se establecieron variables signalíticas, complejas y simples. Las variables, como su nombre lo indica, presentan una propiedad que puede fluctuar y cuya variación es susceptible de medirse u observarse (Hernández Sampieri, Fernández CoIlado \& Baptista Lucio, 2006). En el anexo 1 se presenta la definición conceptual y operacional de las mismas.

\section{Diseño de instrumentos}

Una vez definidas las variables, se procedió a la recolección de datos, para lo cual se elaboró un cuestionario. Para el diseño de este instrumento se utilizaron las variables complejas como categorías. Se asignó un valor numérico a las variables de estudio para vincularlas, en su concepto abstracto, con evidencias empíricas constatables. Constó de cuatro apartados: Título, Datos generales, Instrucciones y Preguntas de contenido (en el anexo 2 se expone la organización y contenido del mismo).

La escala utilizada es una de las más recurridas en la investigación cuantitativa: la Escala Likert; en este caso, de acuerdo con la tabla 1:

Tabla 1

Escala

\begin{tabular}{l|c}
\hline Respuesta & Valor \\
\hline Nada de acuerdo / Nunca / Nada & 0 \\
\hline Poco de acuerdo / Casi nunca / Poco & 1 \\
\hline Regular acuerdo / Algunas veces / Regular & 2 \\
\hline Muy de acuerdo / Casi siempre / Mucho & 3 \\
\hline Totalmente de acuerdo / Siempre / Todo/Totalmente & 4 \\
\hline
\end{tabular}

Fuente: elaboración propia

\section{Población y muestra}

La muestra se definió con base en la población de estudio, esta última es el conjunto de todos los casos que concuerdan con una serie de especificaciones (Claire Selltiz, Lawrence S. Wrigthsman \& Stuart W. Cook, 1980, citados por Hernández Sampieri, Fernández Collado \& Baptista Lucio, 2004). La población estuvo integrada por 3.331 profesores, como se especifica a continuación:

a. 2.881 docentes de escuelas secundarias generales federalizadas del Estado de Chihuahua, quienes laboran en 110 centros de trabajo de toda la entidad.

b. 450 docentes de escuelas telesecundarias de tres municipios del Estado de Guanajuato.

La razón de ubicar la población de estudio en estos grupos poblacionales es conseguir un panorama más amplio de la concepción que se tiene de la planeación didáctica en docentes de secundarias generales de organización completa (con director técnico y gran parte de ellas con subdirector), bajo un sistema de trabajo por asignaturas y con distintos maestros para cada uno de los cursos; y en docentes de telesecundaria, quienes trabajan con un grupo las distintas asignaturas (algunos centros educativos de esta modalidad cuentan con director técnico, y en otros un maestro frente al grupo funge como encargado y realiza funciones directivas). 


\section{Resultados}

Se procedió con base en un esquema de análisis de acuerdo con el diseño de la investigación (tabla 1). Los procedimientos estadísticos se realizaron con apoyo de software especiales para el tratamiento de la información. Las lecturas se llevaron a cabo atendiendo las informaciones relevantes y con apego a los objetivos de la investigación.

Tabla 2

Tratamiento y alcance de los niveles de análisis

\begin{tabular}{l|l|l|l|l}
\hline Nivel & Análisis & Estadísticos & Lecturas & Propósitos \\
\hline Exploratorio & Cronbach & $\begin{array}{l}\text { Ítem análisis } \\
\text { coeficiente de variación } \\
\text { Valor Z }\end{array}$ & $\begin{array}{l}\text { Confiabilidad } \\
\text { Consistencia }\end{array}$ & $\begin{array}{l}\text { Constatar el nivel de confiabilidad y } \\
\text { consistencia de las variables de estudio. }\end{array}$ \\
\hline Caracterización & Enumeración & Frecuencias & $\begin{array}{l}\text { Porcentuales } \\
\text { Proporcionales }\end{array}$ & $\begin{array}{l}\text { Constatar la frecuencia porcentual o } \\
\text { proporcional por población de estudio } \\
\text { con relación a cada variable o grupo de } \\
\text { variables de acuerdo a la escala. }\end{array}$ \\
\cline { 2 - 5 } & Descriptivo & $\begin{array}{l}\text { Medias } \\
\text { Desviación estándar }\end{array}$ & Valores atípicos & $\begin{array}{l}\text { Destacar las variables por grupo de } \\
\text { análisis que presentan comportamientos } \\
\text { extraños con posibilidad paradigmática. }\end{array}$ \\
\hline \hline
\end{tabular}

Fuente: elaboración propia

\section{Características de la población participante}

De los 433 profesores participantes en la investigación predominan los de sexo femenino, del medio laboral urbano $y$, con antigüedad en el servicio entre 9 y 19 años; asimismo quienes tienen edades inferiores a 40 años (56.6\%), mayoritariamente en el rango de 30 a 39 años. Prevalecen egresados de normal superior; pero hay un $24.5 \%$ que cursó otro tipo de licenciatura (no normalista ni relacionada con el campo educativo). Hay preponderancia de quienes realizaron una especialización y una proporción importante (43.8\%) de la maestría como último nivel de estudio. En su mayoría, tienen carga horaria de más de 30 horas, si bien el $36.2 \%$ tiene de 21 a 30 horas.

Tabla 3

Características de la población participante

\begin{tabular}{|c|c|c|c|c|c|c|}
\hline \multicolumn{7}{|c|}{ Total de participantes (Muestra): 433 profesores } \\
\hline \multirow{2}{*}{$\frac{\text { Sexo }}{\text { Medio laboral }}$} & \multirow{2}{*}{$\begin{array}{l}\text { Femenino: } \mathbf{5 3} \% \\
\text { Urbano: } 51 \%\end{array}$} & \multicolumn{5}{|l|}{ Masculino: $\mathbf{4 7 \%}$} \\
\hline & & Semiurbano: $29 \%$ & Rural: $20 \%$ & & & \\
\hline Edad (años) & Menos de $20: 1.4 \%$ & $\begin{array}{l}\text { Entre } 20 \text { y } 29 \text { : } \\
14.5 \%\end{array}$ & $\begin{array}{l}\text { Entre } 30 \text { y } 39 \text { : } \\
40.7 \%\end{array}$ & $\begin{array}{l}\text { Entre } 40 \text { y } 49 \text { : } \\
26.2 \%\end{array}$ & $\begin{array}{l}\text { Entre } 50 \mathrm{y} \\
\text { 59: } 15.7 \%\end{array}$ & $\begin{array}{l}60 \text { o más: } \\
1.4 \%\end{array}$ \\
\hline $\begin{array}{l}\text { Antigüedad en } \\
\text { servicio (años) }\end{array}$ & $0-8: 36 \%$ & 9-19: $43 \%$ & 20 o más: $21 \%$ & & & \\
\hline $\begin{array}{l}\text { Formación } \\
\text { profesional }\end{array}$ & $\begin{array}{l}\text { Normal superior } \\
52.4 \%\end{array}$ & $\begin{array}{l}\text { Licenciatura en } \\
\text { educación } 12.5 \%\end{array}$ & $\begin{array}{l}\text { Otra licenciatura } \\
24.5 \%\end{array}$ & $\begin{array}{l}\text { Normal con } \\
\text { licenciatura } 6.4 \%\end{array}$ & $\begin{array}{l}\text { Normal } \\
\text { básica } 4.2 \%\end{array}$ & \\
\hline Posgrado & Especialización $52.7 \%$ & Maestría $43.8 \%$ & Doctorado $2.5 \%$ & Posdoctorado $1.1 \%$ & & \\
\hline $\begin{array}{l}\text { Carga horaria } \\
\text { (horas) }\end{array}$ & 12 o menos: $6.8 \%$ & 13 a $20: 6.8 \%$ & 21 а $30: 36.2 \%$ & Más de $30: 50.2 \%$ & & \\
\hline $\begin{array}{l}\text { Población } \\
\text { participante }\end{array}$ & $\begin{array}{l}\text { Resto del Estado de } \\
\text { Chihuahua: } 52.8 \%\end{array}$ & $\begin{array}{l}\text { Ciudad Juárez, } \\
\text { Chihuahua: } 24.9 \%\end{array}$ & $\begin{array}{l}\text { Romita, } \\
\text { Guanajuato: } 8.6 \%\end{array}$ & $\begin{array}{l}\text { Guanajuato, } \\
\text { Guanajuato: } 7.0 \%\end{array}$ & $\begin{array}{l}\text { Silao, } \\
\text { Guanajuato: } \\
6.7 \%\end{array}$ & \\
\hline
\end{tabular}

Fuente: elaboración propia 


\section{Análisis exploratorio}

El análisis exploratorio permitió examinar las variables y sus comportamientos. Se empleó el estadístico de Cronbach, con la finalidad de valorar la consistencia interna del cuestionario empleado y constatar que presentara suficiente confiabilidad para poder extender los resultados a toda la población de estudio. Se tomó en cuenta el coeficiente Alpha de Cronbach y se ubicó cada variable en un rango de acuerdo a la tabla 4 :

Tabla 4

Análisis de Cronbach

\begin{tabular}{l|l}
\hline Rango & Lectura \\
\hline Coeficiente alfa $>.9$ & Excelente \\
\hline Coeficiente alfa $>.8$ & Bueno \\
\hline Coeficiente alfa $>.7$ & Aceptable \\
\hline Coeficiente alfa $>.6$ & Cuestionable \\
\hline Coeficiente alfa $>.5$ & Pobre \\
\hline Coeficiente alfa $<.5$ & Inaceptable \\
\hline \hline
\end{tabular}

Fuente: Dolores Frías Navarro (s.f., que cita a Darren George \& Paul Mallery, 2003)

Los resultados obtenidos presentan los siguientes datos:

Tabla 5

Confiabilidad

\begin{tabular}{l|c|c|c|c}
\hline Variables & ac & ac st & Xintercorr. & Os - R \\
\hline 32 & .85 & .87 & .38 & -.03 a .65 \\
\hline $\begin{array}{l}\text { ac = Alpha de Cronbach. } \\
\text { ac st = Alpha de Cronbach } \\
\text { estandarizada. } \\
\begin{array}{l}\text { Xintercorr. Media intercorrelacional. } \\
\text { Os - R }=\text { Puntaje mínimo y máximo de R }\end{array}\end{array}$ & & & & \\
\hline \hline
\end{tabular}

Fuente: elaboración propia

Los resultados indican que las 32 variables en su conjunto presentan un $\mathrm{ac}=.85$; en los rangos de la tabla 3 , el instrumento se ubica entre bueno y excelente; el Alpha estandarizado ac st $=.87$ se ubica un poco más alto, casi en excelente. No obstante, la intercorrelación es de xintercorr. $=.38$, lo cual indica que las variables tienen una interdependencia buena, existiendo una oscilación de $r^{2}=-.03$ hasta $r^{2}=.65$. Esta variación entre las correlaciones se da por la situación de que resultan dos variables con valores negativos.

\section{Frecuencias de cada grupo de variables}

\section{a. Finalidades de la planeación didáctica}

En la gráfica 1 se ilustra la medida con que los docentes recurren a la planeación con finalidades normativa, evaluativa y pedagógica. 
Gráfica 1

Finalidades de la planeación (frecuencia de variables)

\section{¿Para qué planean los docentes?}

10. Para que los estudiantes aprendan contenidos

9. Para desarrollo de competencias de los alumnos

8. Para dosificar contenidos

6. Para mejorar el desempeño de los alumnos

5. Para mejorar indicadores educativos

2. Para organizar mejor mi trabajo

3. Para la evaluación de desempeño

7. Por requisito administrativo

4. Por necesidad laboral

1. Por exigencia de los directivos

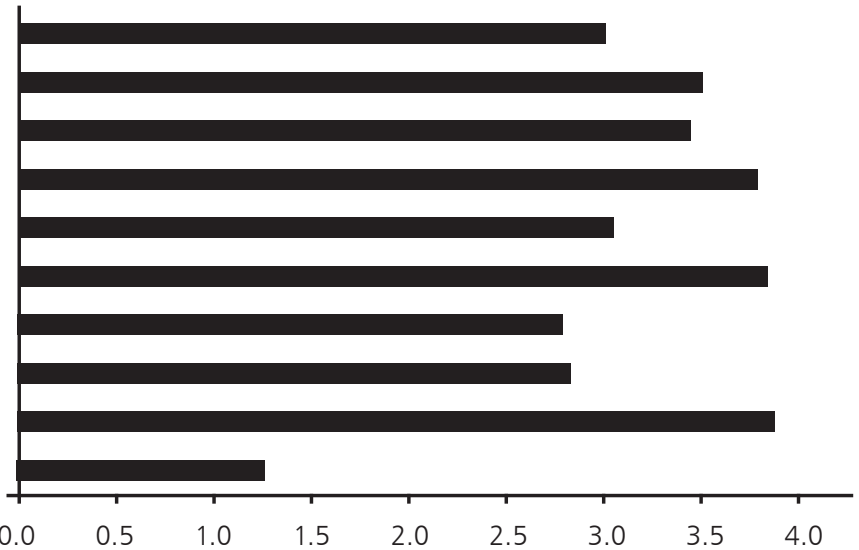

Fuente: elaboración propia

La finalidad normativa tiene la menor ponderación (promedio ponderado: 2.58). La finalidad evaluativa tiene una ponderación más importante que la normativa (2.73); pero predomina la finalidad pedagógica (3.38). Estos resultados dan muestra de la diversidad en las finalidades de la planeación. Predomina el fin pedagógico, no obstante, se presentan elementos importantes respecto a las prácticas de enseñanza tradicional (ponderando contenidos y su dosificación) con valores en las medias muy semejantes a las prácticas formativas (competencias y mejora continua).

\section{b. Enfoques de la planeación didáctica}

La medida con que recurren los docentes a la planeación con enfoque tradicional, vigente y socioformativo, se ilustra en la gráfica 2.

Gráfica 2

Enfoques bajo los que planean los docentes (frecuencia de variables)

\section{¿Bajo qué enfoque planean los docentes?}

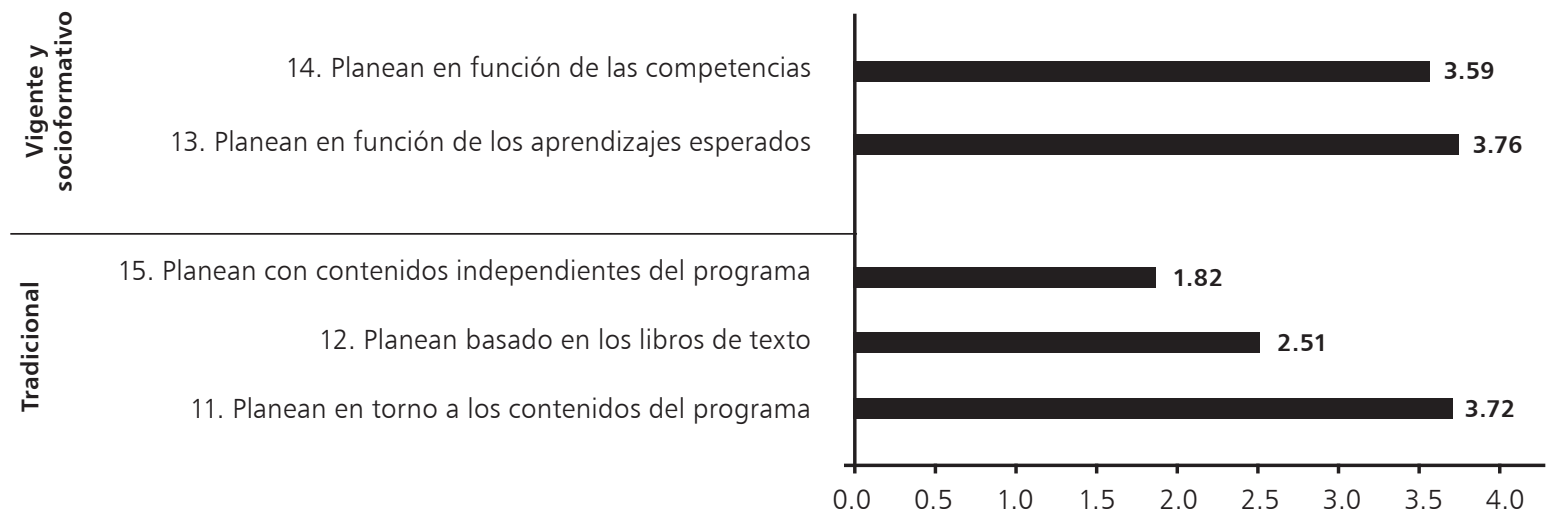

Fuente: elaboración propia 
El enfoque de enseñanza tradicional alcanza una ponderación de 2.68 (promedio ponderado). Por su parte, la del enfoque vigente y socioformativo corresponde a 3.67, lo que denota la predominancia de este último, aun cuando el primero tiene una importante consideración en la planeación que elaboran los docentes.

\section{c. Aspectos de la planeación didáctica}

Los aspectos de la planeación didáctica se agrupan en tres categorías: los que tienen como referencia el enfoque socioformativo, esto es, aquellos aspectos que favorecen el desarrollo de competencias y que estas sean transferidas a situaciones que el estudiante tiene en su ámbito contextual; los que tienen referencia en aspectos argumentativos, esto es, que alcancen a distinguir los motivos y situaciones específicas del porqué de las estrategias, procesos, materiales y evaluación, entre otros. Y finalmente los que tienen como referencia los aspectos básicos o esenciales acorde con el enfoque vigente, como adecuaciones curriculares, instrumentos de evaluación y diversidad de los estudiantes.

En la gráfica 3 se muestra la medida en cuanto a los aspectos básicos, argumentativos y socioformativos que consideran los docentes al realizar la planeación didáctica.

Gráfica 3

Aspectos que toman en cuenta al planear (frecuencia de variables)

\section{Aspectos de la planeación didáctica}

30. Toman en cuenta el proceso metacognitivo (plantean sugerencias para tal fin)

29. Consideran la evaluación por medio de niveles de dominio en matrices o rúbricas

28. Plantean situaciones que demandan la colaboración entre los estudiantes

27. Consideran la formación del compromiso ético de los estudiantes

25. Integran la articulación de actividades en torno a los problemas o situaciones específicas y relevantes del contexto

18. Consideran la definición de criterios y estrategias de evaluación acorde con las competencias a desarrollar

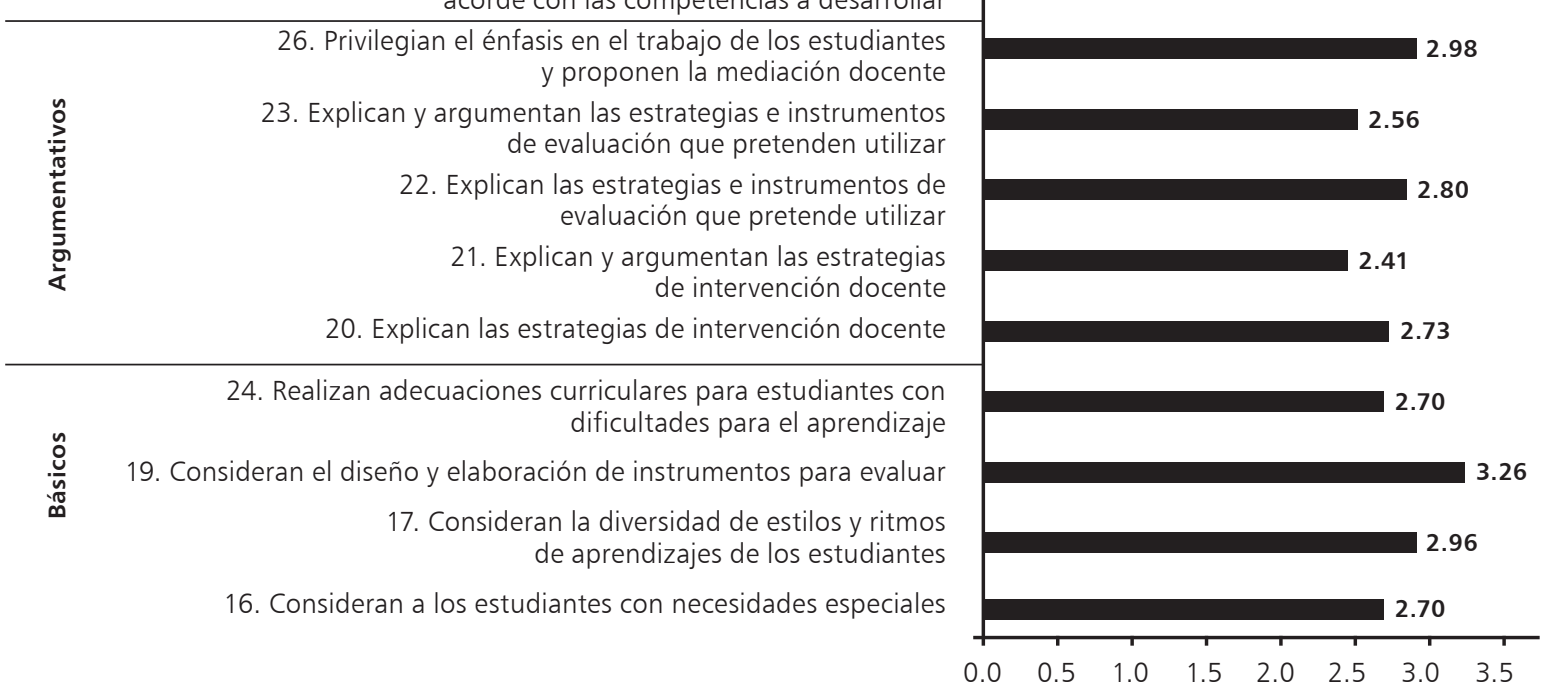

Fuente: elaboración propia 
Los aspectos argumentativos tienen una ponderación (promedio ponderado) de 2.69; le siguen los aspectos básicos (2.90) y, con un valor superior a los dos anteriores (3.05) la correspondiente a los aspectos socioformativos.

Como se advierte, en la planeación de los docentes se da mayor consideración a aspectos socioformativos y la menor corresponde a los argumentativos, si bien esta última está en la misma tendencia ("muy de acuerdo") que la de aspectos básicos.

\section{Análisis descriptivo}

Con el propósito de revisar las categorías de análisis en cuanto a la descripción de las variables que integran cada uno de esos conjuntos, se realizó el análisis de las medias y con ello se identificó el comportamiento de las variables de estudio. Para ello se recurrió a la utilización del comportamiento de las variables respecto de la ubicación dentro de la curva normal, esto es, se revisó cuáles de ellas se ubican en la condición de "normal" y cuáles presentan un comportamiento "extraño" o atípico. Este procedimiento de análisis estadístico produce información relevante y orientaciones con alta precisión en cuanto a la detección de casos extraños en cada grupo de variables. Aunque también se ubica en el nivel descriptivo, pasa de ser simple enumeración por frecuencias a la caracterización del fenómeno.

Gráfica 4

Finalidades de la planeación didáctica (valores atípicos)
Los valores atípicos se delimitan a partir del análisis de la varianza que presenta cada variable respecto al resto de las variables del grupo o categoría de análisis. Se toma como referencia la media de las medias $\left(X^{\prime}\right)$ del grupo de variables y de acuerdo a la variación dada por la desviación estándar ( $\sigma$ ) se establece la zona de comportamiento normal al $68 \%$ de las variables que corresponde a $X \in\left[X^{\prime} \pm 1 \sigma\right]$; por tanto, se considera valor atípico o extraño todas aquellas variables que se ubican fuera de este rango, para definir los valores extraños como positivos o negativos según corresponda su ubicación, así los valores atípicos superiores serán los que se ubiquen en el rango $\mathrm{N}+\geq \mathrm{X}^{\prime}+1 \sigma$ y los atípicos inferiores los que se ubican en el rango $N-\leq X^{\prime}-1 \sigma$.

Los casos de variables con comportamiento atípico presentan un foco de atención y dan la posibilidad de generar paradigma, o mejor dicho, una perspectiva nueva o distinta del fenómeno que se estudia. Al respecto, a continuación se presentan aquellos grupos de variables por sujetos de estudio y sus respectivas lecturas.

\section{Valores atípicos en cada una de las categorías de análisis a. Finalidades de la planeación didáctica}

En cuanto al para qué planean los docentes, en la gráfica 4 se indica (con relleno de trama rombos) el valor atípico inferior identificado.

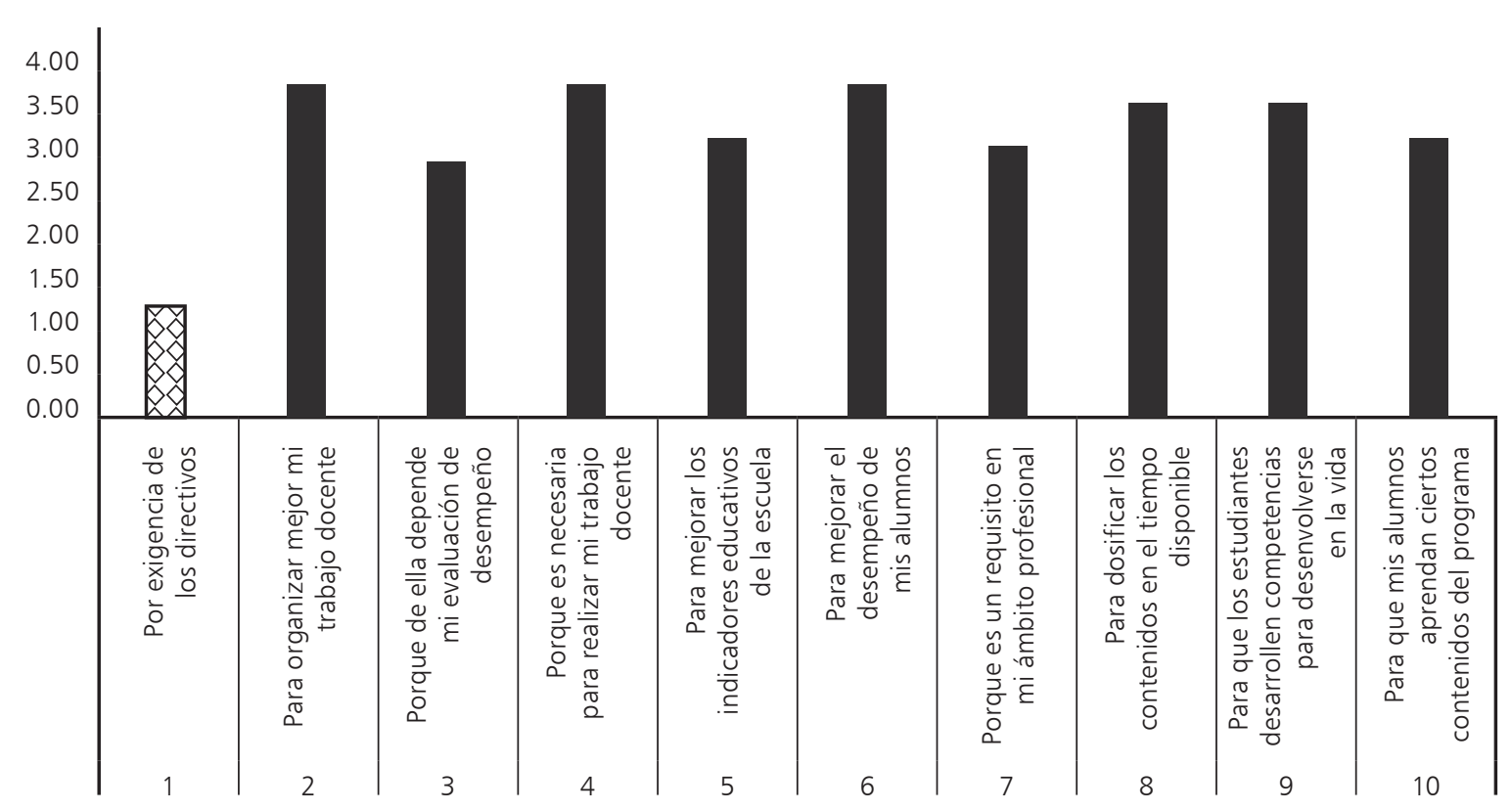

Fuente: elaboración propia 
Esto representa que la población de estudio da poca consideración a realizar la planeación didáctica para atender la exigencia de los directivos (variable 1). Este hallazgo es muy relevante, porque además, esta variable corresponde a la finalidad normativa la cual, como se ha señalado en el subapartado Frecuencias de cada grupo de variables, inciso Finalidades de la planeación didáctica, es la que tiene menor consideración por parte de los docentes de secundaria.

\section{b. Enfoques de la planeación didáctica}

Como se muestra en la gráfica 5 - con relleno de trama rombos-, la variable 15 tiene valor atípico inferior.

Gráfica 5

Enfoques de la planeación didáctica (valores atípicos)

\section{Yo realizo la planeación en torno a...}

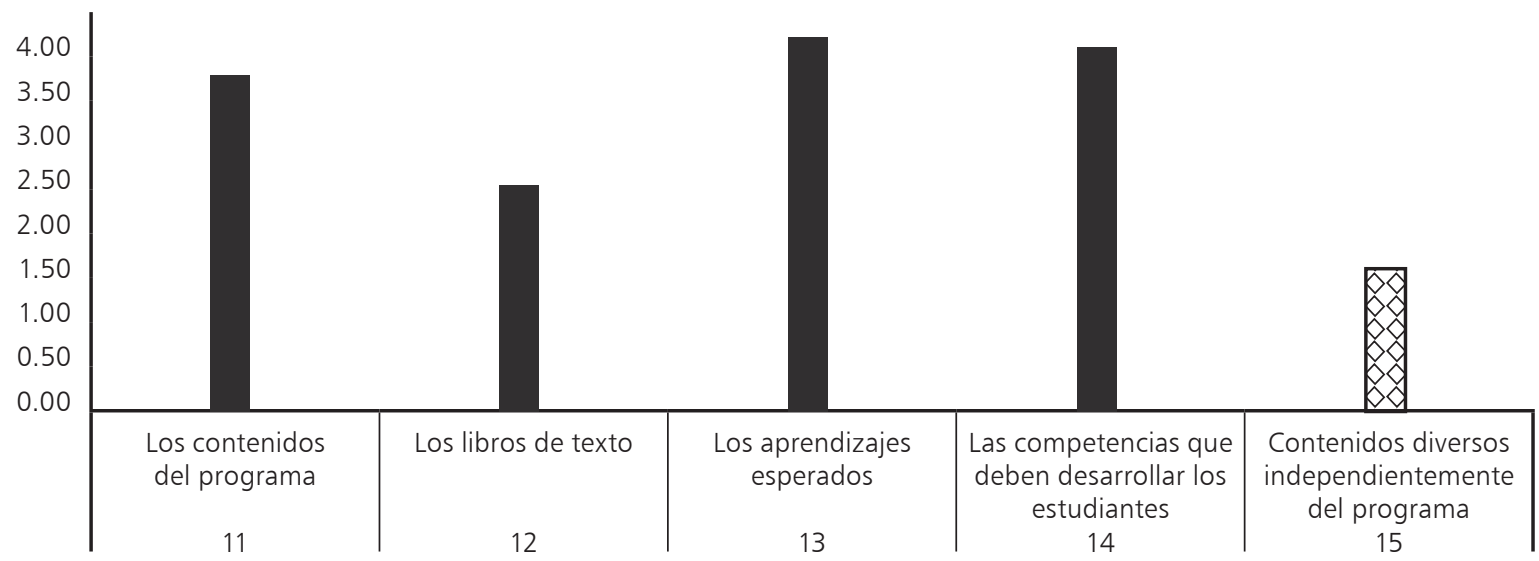

Fuente: elaboración propia

Esto indica que si bien, como se ha dicho en el subapartado Frecuencias de cada grupo de variables, inciso Enfoques de la planeación didáctica, aún persiste de manera importante la tendencia de planear con base en el enfoque tradicionalista, los profesores toman como referentes esenciales los contenidos que se señalan en el programa de la asignatura que corresponda, pues en el diseño curricular estos están alineados con los aprendizajes esperados y las competencias que se pretende desarrollen los estudiantes.

\section{c. Aspectos de la planeación didáctica}

En cuanto a los aspectos que se consideran al integrar la planeación didáctica, en la gráfica 6 se señalan las variables con valor atípico inferior —relleno de trama rombos-y la que obtuvo valor atípico superior —relleno de trama cuadrícula-.

La variable atípica inferior (variable 21) es un indicio de que los profesores tienen dificultades para argumentar lo que planean; sin embargo, no recibir apoyo y asesoría para diseñar tal herramienta básica del trabajo docente (variable 32) alerta sobre la necesidad urgente de ofrecer estos elementos para fortalecer el trabajo docente y, en consecuencia, el desarrollo de las competencias para la vida y el logro del perfil de egreso previsto en el Plan de Estudios de Educación Básica. 
Gráfica 6

Aspectos de la planeación didáctica (valores atípicos)

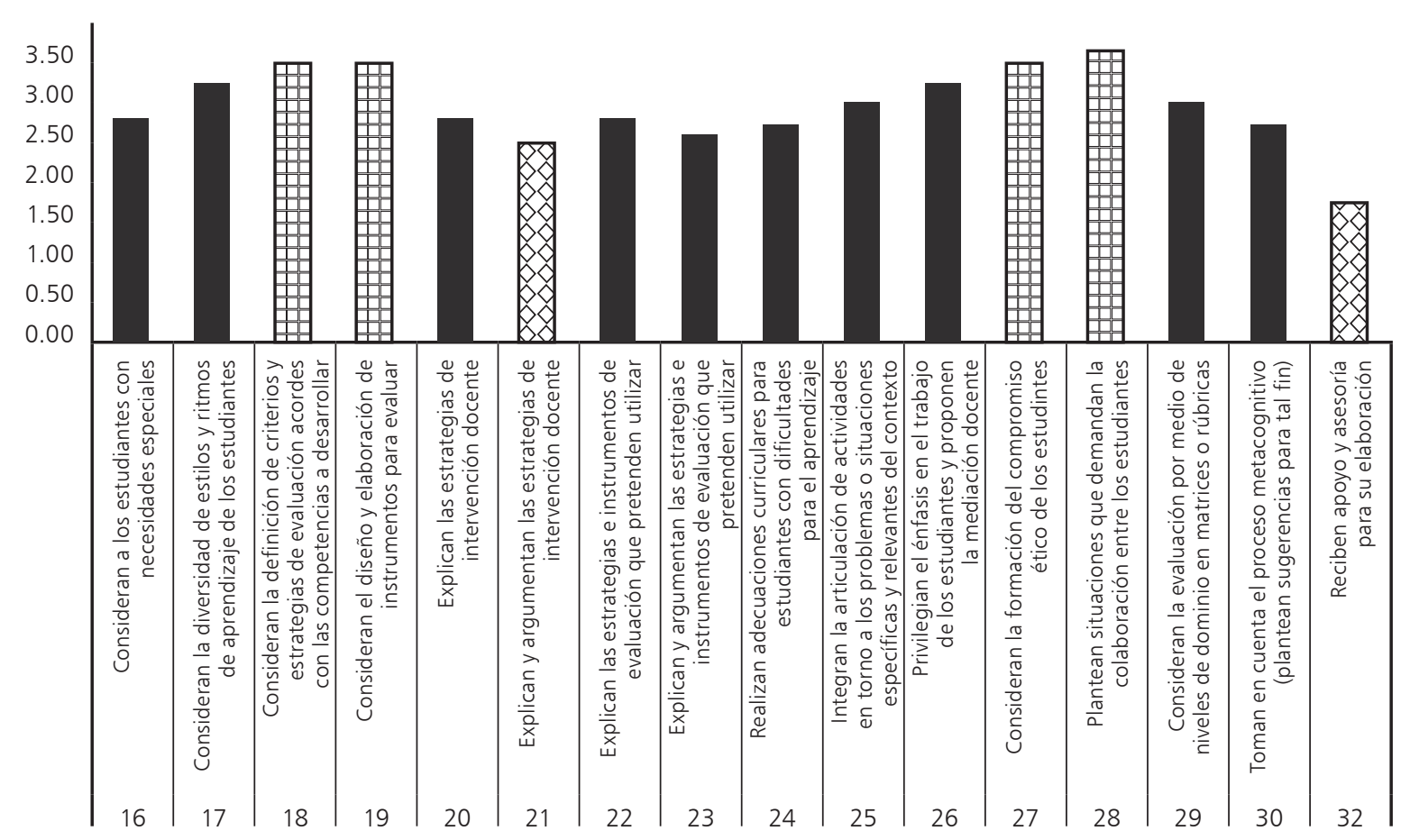

Fuente: elaboración propia

Por su parte, las variables atípicas superiores (variable 18, 19, 27 y 28) dan cuenta de la gran consideración que los docentes dan al diseño y elaboración de instrumentos para evaluar con estrategias de evaluación acordes a las necesidades de los estudiantes, además de aquellos aspectos que son propios de la socioformación, como el compromiso ético y la promoción de la colaboración. Estos aspectos son útiles para valorar logros y dificultades en los aprendizajes así como fortalecer el mejoramiento personal y social, lo cual atina con el perfil de egreso de la educación básica.

\section{Discusión de resultados}

Como se ha mostrado, en la planeación didáctica predomina la finalidad pedagógica. Los profesores de educación secundaria planean la enseñanza porque la consideran parte importante de la organización de su trabajo y elemento con base en el cual promueven que los estudiantes desarrollen las competencias y logren el perfil de egreso previstos en el plan de estudios.

Aun cuando se reconoce, en gran medida, como una necesidad laboral (aspecto normativo) y tal herramienta del trabajo docente se ha constituido como un elemento evaluativo en el marco de la Reforma Constitucional Mexicana en el ámbito educativo (México, 2013; SEP, 2015a, 2015b, 2015c); es destacable la poca consideración (valor atípico inferior) que los profesores dan a planear para cumplir con la exigencia de los directivos. Estos hallazgos hacen suponer autonomía y responsabilidad profesional, elementos de las competencias éticas de los docentes (García García, 2010) que contribuyen al mejoramiento de la calidad de la educación básica de nivel secundaria. 
En cuanto a los enfoques pedagógicos que sustentan la planeación didáctica, predominan el vigente y socioformativo, lo que evidencia una alta consideración a planear en función de las competencias y de los aprendizajes esperados, con los alumnos y sus logros educativos como eje (SEP, 2011b); sin embargo, hay una importante consideración del enfoque tradicional y sobresale el hecho de planear centrando la atención en los contenidos, pero sin considerar otros ajenos a los señalados en los programas de las asignaturas (valor atípico inferior). Esto es un aspecto muy recurrido en las prácticas docentes, se planea la secuencia didáctica con el enfoque vigente y socioformativo como base, no obstante en la práctica se recurre a lo tradicional. Por otra parte, en este estudio se identifica una tendencia muy acentuada en aspectos basados en las competencias y contexto de los estudiantes, por tanto, puede decirse que la planeación didáctica cumple con lo establecido en los programas de estudio y sus consideraciones; pero en la realidad de las aulas las prácticas se desprenden del discurso planteado por los docentes y se sigue utilizando mayormente con fines administrativos.

Respecto de los aspectos de la evaluación, aun cuando se da mucha consideración a los tres tipos (básicos, argumentativos y socioformativos), hay predominancia de los socioformativos y sobresalen función mediadora del docente, trabajo colaborativo entre estudiantes, formación del compromiso ético y, definición de criterios y estrategias evaluativas en correspondencia con las competencias a desarrollar (Tobón, González, Nambo \& Vázquez, 2015; Tobón, Pimienta Prieto \& García Fraile, 2010).

Es destacable que el aspecto argumentativo tenga la menor ponderación, y sobre todo las variables explícitamente relacionadas con argumentar (el empleo de determinadas estrategias de intervención docente; así como estrategias e instrumentos de evaluación); esto podría deberse a la complejidad que suele representar el planteamiento de un razonamiento o conjunto de razonamientos destinado a probar o justificar una decisión o conclusión (Larraín, Freire \& Olivos, 2014), máxime que como discurso escrito tal demanda es reciente (México, 2013; SEP, 2015a, 2015c) y por tanto hay poco ejercicio formal al respecto.

Aunado a lo antes señalado, el hallazgo de la predominancia del enfoque vigente y socioformativo en la planeación didáctica contrasta con resultados del estudio realizado por Adriana del Carmen Toalá Valdez (2010), pues los profesores participantes en la presente investigación consideran asumir la planeación didáctica con base en el enfoque de competencias; si bien como lo señalan también es necesario apoyo y asesoría, lo cual está estipulado en el Plan de Estudios de Educación Básica: "...La asesoría es un acompañamiento que se da a los docentes para la comprensión e implementación de las nuevas propuestas curriculares. Su reto está en la resignificación de conceptos y prácticas" (Gobierno de México, SEP, 2011b, p. 41).

Finalmente, se reconoce que este estudio tiene sus limitaciones, puesto que se inserta en un nivel educativo en específico, lo cual presenta una cara de un problema mucho más amplio. Ante esto, es conveniente que los resultados que se muestran en este artículo sean detonantes para futuras investigaciones, sobre todo, desde un enfoque más profundo y humanista que dé cuenta a la vez de aquellos aspectos inherentes al desarrollo humano tanto del docente como de los estudiantes para quienes se desarrolla la planeación didáctica.

\section{Conclusiones}

Las disposiciones que se han planteado en los procesos de evaluación al docente han generado confusión y preocupación al no contar con orientaciones específicas; esto ha llevado a los docentes a buscar información en distintos medios; se observa una gran diversidad de finalidades, enfoques y aspectos que toman en cuenta al elaborar sus planeaciones. Por otra parte, manifiestan que no han recibido asesoría para llevarla a cabo. Entre otras situaciones se pudo constatar que los docentes toman los aprendizajes esperados como referentes para la planeación didáctica, pero se proponen prácticas educativas bajo enfoques de enseñanza no muy bien definidos y en los cuales hay elementos para considerar que el enfoque socioformativo se desarrolla en algunos de sus elementos teóricos.

Con base en los resultados obtenidos con esta investigación se identifican aspectos muy importantes que dan respuesta a las situaciones mencionadas en el párrafo anterior. En primer lugar, respecto de las finalidades de su planeación didáctica, como todo documento elaborado por los docentes, la realización de esta herramienta de la práctica educativa también tiene un para qué; en tal sentido, las pedagógicas son las que presentan mejores resultados; en especial, los profesores sostienen que realizan la planeación didáctica para organizar mejor su trabajo y con ello mejorar el desempeño de sus estudiantes en cuanto al desarrollo de competencias; no obstante, entre estas prácticas se entrelazan algunas que corresponden al enfoque vigente y socioformativo pero hay otras que alcanzan bastante fuerza y que se anclan en las prácticas tradicionales.

Planear la enseñanza para prepararse para la evaluación del desempeño docente no resultó muy relevante. Elaborarla con fines normativos tiene dos connotaciones principales: lo hacen por necesidad laboral y por requisito administrativo; y es destacable que en menor medida, esto es, muy pocos docentes la elaboran 
por exigencia de los directivos. Esta independencia de las exigencias de sus autoridades educativas inmediatas y considerarla en gran medida como parte de su tarea educativa abre una veta de investigación en torno a la ética profesional de los docentes de secundaria, en el marco de la implementación del Plan de Estudios de Educación Básica.

El segundo aspecto analizado es el referente al enfoque que toman los profesores para elaborar su planeación didáctica, y en este caso, se revisó desde dos perspectivas: el enfoque tradicional y, el vigente y socioformativo. Respecto del primero, encontramos que los docentes planean en función de los contenidos y aún prevalece el uso de los libros de texto como sustento de tal tarea profesional; con menor medida se utilizan contenidos fuera del programa, es decir, algunos profesores en cierto momento se apoyan en otros temas y contenidos que consideran deben aprender los estudiantes de secundaria. En cambio, el enfoque vigente y socioformativo es el que predomina; ya que consideran, en gran medida, la planeación en función de las competencias a desarrollar y con base en los aprendizajes esperados previstos en los programas de las asignaturas.

Finalmente, en correspondencia con la predominancia del enfoque vigente y socioformativo, en cuanto a los aspectos que integran o toman en consideración al planear, los docentes buscan desarrollar el trabajo colaborativo entre los estudiantes y la formación de un proyecto ético de vida; asimismo, definen criterios y estrategias de evaluación acordes con las competencias que promueven que desarrollen los alumnos. Esto último se refuerza con la fuerte importancia que dan al diseño y elaboración de instrumentos para evaluar los aprendizajes. Por otra parte, en cuanto a aspectos argumentativos destacan la explicación que se logra hacer respecto de las estrategias de intervención docente y, de las estrategias e instrumentos para evaluar los aprendizajes; si bien falta fortalecer su argumentación.

Con estos primeros resultados se observa un gran avance en el trabajo que desarrollan los docentes con orientaciones hacia el enfoque socioformativo, aunado a que lo hacen por responsabilidad profesional, más que por exigencia de los directivos o demanda con fines de evaluación por parte del sistema educativo; pero también se advierte la necesidad de ofrecerles apoyo y asesoría para fortalecer el diseño de sus planeaciones didácticas y la argumentación en torno a ello.

La función del docente no implica el diseño, la elaboración y la puesta en práctica de la planeación didáctica, sino todo lo contrario; la planeación didáctica es una práctica educativa que implica la función docente. Es un elemento constitutivo de las tareas que se llevan a cabo en el aula; no puede concebirse una clase si no está previamente organizada, preparada, pensada y con los suficientes argumentos para justificar tal o cual actividad para el logro de los aprendizajes esperados de los estudiantes.

Sin duda, los hallazgos del estudio son de gran valía para el conocimiento en torno al objeto y la finalidad prevista; pero también reconocemos que se trata de un primer acercamiento por lo cual será necesario dar continuidad y, por ejemplo, definir si hay diferencias en la forma en que asumen el diseño de la planeación didáctica dependiendo de la modalidad de secundaria en que trabajan los profesores, de su formación profesional y de su antigüedad en el servicio; en ese caso, cuáles son estas. Por otra parte, será necesario abordar el estudio con otra perspectiva metodológica, analizar planes de clase que diseñan los profesores, lo cual permitirá ahondar en el diagnóstico sobre las necesidades de apoyo para avanzar en el desarrollo de competencias docentes que les permitan aplicar el enfoque del Plan de Estudios de Educación Básica y fortalecer el desarrollo de las competencias para la vida y el logro del perfil de egreso. 


\section{Sobre los autores}

Maribel Brito-Lara es académica de la Escuela Normal Superior Oficial de Guanajuato, México. Miembro del Cuerpo Académico ENSOG-CA-1, reconocido por el Programa de Desarrollo Profesional de la Secretaría de Educación Pública. Estudiante del doctorado en Socioformación y Sociedad del Conocimiento en el Centro Universitario Ciencia e Innovación para la Formación y el Emprendimiento (CIFE).

José López-Loya es integrante del núcleo básico de CIFE en el programa doctoral. Integrante del núcleo básico del doctorado del Centro de Investigación y Docencia. Docente investigador.

Haydeé Parra-Acosta es integrante del núcleo básico de CIFE en el programa doctoral. Integrante del núcleo básico del doctorado del Centro de Investigación y Docencia. Investigadora de la Universidad Autónoma de Chihuahua, México.

\section{Referencias}

Alliaud, A. \& Vezub. L. (2015). Los saberes docentes en la mira: una aproximación polifónica. Revista de la Escuela de Ciencias de la Educación, 11 (10), 111-130. Recuperado de http://www.revistacseducacion.unr. edu.ar/ojs/index.php/educacion/article/view/227

Alonso-Tejeda, M. E. (2009). Teorías del aprendizaje y la planeación didáctica. Cuadernos de Formación de Profesores No. 3, Teorías del aprendizaje y la planeación didáctica. Disponible en: http://uiap. dgenp.unam.mx/apoyo_pedagogico/proforni/antologias/LA\%20 PLANEACION\%20DIDACTICA.pdf

Coll-Salvador, C.; Bustos-Sánchez, A. \& Engel, A. (2008). Las comunidades virtuales de aprendizaje. En C. Coll \& C. Monereo (eds.). Psicología de la educación virtual. Aprender y enseñar con las Tecnologías de la Información y la Comunicación, 299-320. Madrid: Morata.

Díaz-Barriga Arceo, F. (2006). Enseñanza situada. Vínculo entre la escuela y la vida. Ciudad de México: Trillas. Disponible en: https://www.uv.mx/ rmipe/files/2016/08/Ensenanza-situada-vinculo-entre-la-escuela-yla-vida.pdf

Díaz-Barriga Arceo, F. \& Hernández-Rojas, G. (2010). Estrategias docentes para un aprendizaje significativo. Ciudad de México: Trillas.

Dueñez-Serrano, F. \& Barraza-Macías, A. (2015). La formación inicial como determinante del quehacer y ser docente, y su relación con el aprendizaje de los alumnos. Ciudad de México: Instituto Universitario Anglo Español. Disponible en: http://www.upd.edu.mx/PDF/Libros/LibroFer nando.pdf

Flórez-Petour, M. T. (s.f.). Modelos pedagógicos y planificación: un poco de historia. Disponible en: https://goo.gl/QCxGDg

Frías-Navarro, D. (2003). Alfa de Cronbach y consistencia interna de los items de un instrumento de medida. Disponible en: https://www. uv.es/ friasnav/AlfaCronbach.pdf

García-García, E. (2010). Competencias éticas del profesor y calidad de la educación. Revista Electrónica Interuniversitaria de Formación del Profesorado, REIFOP, 13 (4), 29-41. Disponible en: https://www.aufop.com/aufop/revistas/arta/digital/155/1613, https://www.aufop. com/aufop/uploaded_files/articulos/1291992474.pdf

Gobierno de México, Secretaría de Educación Pública, SEP (2011a). Acuerdo 592 por el que se Establece la Articulación de la Educación Básica. Ciudad de México: SEP. Disponible en: http://www.sipi.siteal.iipe. 
unesco.org/sites/default/files/sipi_normativa/acuerdo_592_articula cion_educacion_basica_primaria.pdf

Gobierno de México, Secretaría de Educación Pública, SEP (2011b). Plan de estudios de educación básica. Ciudad de México: SEP. Disponible en: https://www.gob.mx/cms/uploads/attachment/file/20177/Plan_de_ Estudios_2011_f.pdf

Gobierno de México, Secretaría de Educación Pública, SEP (2012). La evaluación durante el ciclo escolar. Serie: Herramientas para la Evaluación en Educación Básica. Ciudad de México: SEP. Disponible en: http://www.seslp.gob.mx/consejostecnicosescolares/PRIMARIA/6DOCUMENTOSDEAPOYO/LIBROSDEEVALUACION2013/2-LAEVAL DURANTEELCICLOESCOLAR.pdf

Gobierno de México, Secretaría de Educación Pública, SEP (2015a). Etapas, aspectos, métodos e instrumentos. Proceso de evaluación del desempeño docente. Educación básica. Ciudad de México: SEP. Disponible en: http://servicioprofesionaldocente.sep.gob.mx/content/ba/ docs/2015/permanencia/etapas_aspectos/VERSION_FINAL_dmj_do centes 190515.pdf

Gobierno de México, Secretaría de Educación Pública, SEP (2015b). Guía técnica. Planeación didáctica argumentada. Secundaria. Matemáticas. Docentes. Ciudad de México: SEP. Disponible en: http://serviciopro fesionaldocente.sep.gob.mx/content/ba/docs/2015/permanencia/ PLANEACION_DIDACTICA/VF_GUIAS_TECNICAS_PLANEACION_DI DACTICA_ARGUMENTADA/5_GUIA_TECNICA_PLANEACION_DO CENTES_SECU-MATE.pdf

Gobierno de México, Secretaría de Educación Pública, SEP (2015c). Perfil, parámetros e indicadores para docentes y técnicos docentes. Evaluación del desempeño docente, ciclo escolar 2015-2016. Ciudad de México: SEP. Disponible en: http://servicioprofesionaldocente.sep. gob.mx/content/ba/docs/2015/permanencia/parametros_indicadores/PPI_DESEMPENO\%20DOCENTE_TECDOCENTES.pdf

Gobierno de México, Secretaría de Educación Pública, SEP (2017). Modelo educativo para la educación obligatoria. Ciudad de México: SEP. Disponible en: https://www.gob.mx/cms/uploads/attachment/file/198738/ Modelo_Educativo_para_la_Educacio_n_Obligatoria.pdf

Guzmán, J. C. (coord.) (2013). Del currículum al aula. Orientaciones y sugerencias para aplicar la RIEB [Reforma Integral de Educación Básica]. Barcelona: Graó.

Hernández-Sampieri, R.; Fernández-Collado, C. \& Baptista-Lucio, P. (2004). Metodología de la Investigación. $3^{a}$ ed., Ciudad de México: Editorial McGraw Hill.

Hernández-Sampieri, R.; Fernández-Collado, C. \& Baptista-Lucio, P. (2006). Metodología de la investigación. $4^{a}$ ed., Ciudad de México: Editorial McGraw Hill.

Larraín, A.; Freire, P. \& Olivos, T. (2014). Habilidades de argumentación escrita: una propuesta de medición para estudiantes de quinto básico. Psicoperspectivas, 13 (1), 94-107. Disponible en: http://www.psicoperspectivas.cl/index.php/psicoperspectivas/article/viewFile/287/316

Melitón-García, I. \& Valencia-Martínez, M. (2014). Nociones y prácticas de la planeación didáctica desde el enfoque por competencias de los formadores de docentes. Ra Ximhai, 10 (5), 15-24. Disponible en: http://www.redalyc.org/pdf/461/46132134001.pdf

México (2013). Ley general del servicio profesional docente. Diario Oficial de la Federación, 11 de septiembre de 2013. Disponible en: http://www. dof.gob.mx/nota_detalle.php?codigo $=5313843 \&$ fecha $=11 / 09 / 2013$ 
Moya-López, M. (2013). Los pilares de la educación y la interculturalidad. Una aplicación práctica para trabajar la educación intercultural desde las imágenes y la música. Global Education Magazine: School Day of Non-violence and Peace. Disponible en: http://www.globaleduca tionmagazine.com/global-education-magazine-2/

Navarro-Rodríguez, M. \& Telles-Contreras, M. C. (2013). La planeación didáctica en la escuela primaria: una perspectiva desde los profesores. En A. Barraza Macías, M. Navarro Rodríguez \& A. Jaik Dipp (coords.). Estudios en México sobre los agentes educativos, 74-90. Ciudad de México: Red Durango de Investigadores Educativos A.C., ReDIE. Disponible en: https://goo.gl/8ULtKV

Parra-Acosta, H.; Tobón, S. \& López-Loya, J. (2015). Docencia socioformativa y desempeño académico en la educación superior. Revista Paradigma, 36 (1), 42-55. Disponible en: http://revistas.upel.edu.ve/index. php/paradigma/article/view/2653/1267

Ribes-Iñesta, E. (2008). Educación básica, desarrollo psicológico y planeación de competencias. Revista Mexicana de Psicología, 25 (2), 193-207. Disponible en: http://www.redalyc.org/pdf/2430/24301 6308001.pdf

Serrano-González-Tejero, J. M. \& Pons-Parra, R. M. (2011). El constructivismo hoy: enfoques constructivistas en educación. Revista Electrónica de Investigación Educativa, REDIE, 13 (1), 1-27. Disponible en: https://redie. uabc.mx/redie/article/view/268/708

Tacca-Huamán, D. R. (2011). El "nuevo" enfoque pedagógico: las competencias. Revista Investigación Educativa, 15 (28), 163-185. Disponible en: http://revistasinvestigacion.unmsm.edu.pe/index.php/educa/article/ view/5426/4673

Tenutto, M.; Brutti, C. \& Algarañá, S. (2010). Planificar, enseñar, aprender y evaluar por competencias. Conceptos y propuestas. Buenos Aires: Digital y Papel. Disponible en: http://www.nuestraldea.com/wpcontent/uploads/2011/05/planificar-ensenar-aprender-y-evaluar-porcompetencias.pdf

Toalá-Valdez, A. C. (2010). Retos y desafíos de los docentes de secundaria en la implementación del enfoque basado en competencias. Tesis de maestría. Escuela Superior de Comercio y Administración, Unidad Santo Tomás, Sección de Estudios de Posgrado e Investigación del Instituto Politécnico Nacional. Disponible en: https://tesis.ipn.mx/ jspui/bitstream/123456789/13696/1/TESIS\%20_Adriana\%20Toala. pdf

Tobón, S. (2013). Formación integral y competencias. Pensamiento complejo, currículo, didáctica y evaluación. Bogotá: ECOE Ediciones.

Tobón, S.; González, L.; Nambo, J. S. \& Vázquez A., J. M. (2015). La socioformación: un estudio conceptual. Revista Paradigma, 36 (1), 7-29. Disponible en: http://revistas.upel.edu.ve/index.php/paradigma/arti cle/view/2661/1273

Tobón-Tobón, S.; Pimienta-Prieto, J. H. \& García-Fraile, J. A. (2010). Secuencias didácticas: aprendizaje y evaluación de competencias. Ciudad de México: Pearson Editores. http://files.ctezona141.webnode. $\mathrm{mx} / 200000004-8$ ed038fca3/secuencias-didacticastobon-120521 222400-phpapp02.pdf

Viloria, N. \& Godoy, G. (2010). Planificación de estrategias didácticas para el mejoramiento de las competencias matemáticas de sexto grado. Investigación y Postgrado, RevInPost, 25 (1), 95-116. Disponible en: http://www.redalyc.org/pdf/658/65822264006.pdf 
Anexo 1

Definición conceptual y operacional de las variables

\begin{tabular}{|c|c|c|c|}
\hline $\begin{array}{l}\text { Variables } \\
\text { complejas }\end{array}$ & Definición conceptual & $\begin{array}{l}\text { Definición } \\
\text { operacional }\end{array}$ & Variables simples \\
\hline I. Signalíticas & $\begin{array}{l}\text { Corresponde a los "signos o señas" } \\
\text { que den cuenta de las características } \\
\text { de los sujetos. Comúnmente, se } \\
\text { enuncian como datos generales de la } \\
\text { población de estudio. }\end{array}$ & $\begin{array}{l}\text { Variación de } \\
\text { condiciones } \\
\text { personales y } \\
\text { laborales de los } \\
\text { sujetos. }\end{array}$ & $\begin{array}{l}\text { Contexto de la escuela, sexo, edad, } \\
\text { preparación profesional, último grado de } \\
\text { estudios, carga horaria, antigüedad en el } \\
\text { servicio. }\end{array}$ \\
\hline $\begin{array}{l}\text { II. Finalidades } \\
\text { del diseño de la } \\
\text { planeación de } \\
\text { clases }\end{array}$ & $\begin{array}{l}\text { Finalidad como intencionalidad. } \\
\text { Intención que tiene el docente para } \\
\text { elaborar su planeación didáctica: } \\
\text { normativa, evaluativa, o pedagógica } \\
\text { (mejora de la enseñanza y de los } \\
\text { aprendizajes). }\end{array}$ & $\begin{array}{l}\text { Medida en que } \\
\text { los docentes } \\
\text { consideran la } \\
\text { elaboración de } \\
\text { la planeación } \\
\text { didáctica en } \\
\text { función de } \\
\text { los propósitos } \\
\text { educativos. }\end{array}$ & $\begin{array}{l}\text { Normativa: exigencia de los directivos; } \\
\text { requisito laboral, necesidad laboral. } \\
\text { Evaluativa: evaluación del desempeño. } \\
\text { Pedagógica: organización, mejora de } \\
\text { indicadores, mejorar el desempeño de los } \\
\text { estudiantes, dosificar contenidos, desarrollar } \\
\text { competencias en los estudiantes y para el } \\
\text { aprendizaje de contenidos. }\end{array}$ \\
\hline $\begin{array}{l}\text { III. Enfoques de } \\
\text { la planeación } \\
\text { didáctica }\end{array}$ & $\begin{array}{l}\text { El enfoque es la posición desde } \\
\text { donde el docente soporta el } \\
\text { desarrollo de la planeación didáctica. } \\
\text { En este estudio se toman dos } \\
\text { grandes perspectivas: el enfoque } \\
\text { tradicional que se sustenta en los } \\
\text { contenidos del programa, la función } \\
\text { administrativa, la centralidad en el } \\
\text { docente; y el enfoque vigente, que } \\
\text { promueve la mejora continua de los } \\
\text { aprendizajes y con ello se ubica el } \\
\text { enfoque socioformativo. }\end{array}$ & $\begin{array}{l}\text { Medida en que } \\
\text { los docentes } \\
\text { incluyen en } \\
\text { el diseño de } \\
\text { la planeación } \\
\text { de clases } \\
\text { los aspectos } \\
\text { que definen } \\
\text { el enfoque } \\
\text { pedagógico. }\end{array}$ & $\begin{array}{l}\text { Enfoque tradicional: diseño basado en: } \\
\text { contenidos del programa, contenidos } \\
\text { diversos independientemente del programa y } \\
\text { libros de texto. } \\
\text { Enfoque vigente y socioformativo: diseño en } \\
\text { función de los aprendizajes esperados y las } \\
\text { competencias. }\end{array}$ \\
\hline $\begin{array}{l}\text { IV. Aspectos de } \\
\text { la planeación } \\
\text { didáctica }\end{array}$ & $\begin{array}{l}\text { La planeación didáctica se diseña } \\
\text { a partir de los elementos que la } \\
\text { constituyen. Estos se clasifican en } \\
\text { diversos tipos: los básicos, que son } \\
\text { aquellos que la estructura de la } \\
\text { planeación didáctica contiene; los } \\
\text { de argumentación, que son aquellos } \\
\text { que se incluyen para justificar las } \\
\text { estrategias de intervención docente; } \\
\text { y finalmente los que enmarcan el } \\
\text { enfoque socioformativo, es decir, } \\
\text { aquellos elementos que enfatizan } \\
\text { el desarrollo ético de vida de los } \\
\text { estudiantes y la mediación docente. }\end{array}$ & $\begin{array}{l}\text { Medida en que } \\
\text { los aspectos } \\
\text { básicos, de } \\
\text { argumentación y } \\
\text { socioformativos } \\
\text { son tomados en } \\
\text { cuenta por los } \\
\text { docentes para } \\
\text { el diseño de } \\
\text { su planeación } \\
\text { didáctica. }\end{array}$ & $\begin{array}{l}\text { Aspectos básicos de la planeación didáctica: } \\
\text { atención específica a estudiantes con } \\
\text { NEE [Necesidades Educativas Especiales]; } \\
\text { diversidad en los estilos y ritmos de } \\
\text { aprendizaje; diseño y elaboración de } \\
\text { instrumentos de evaluación; adecuaciones } \\
\text { curriculares para estudiantes con dificultades } \\
\text { para el aprendizaje. } \\
\text { Aspectos de argumentación: explica y } \\
\text { argumenta estrategias de intervención } \\
\text { docente, estrategias e instrumentos de } \\
\text { evaluación y mediación docente. } \\
\text { Aspectos socioformativos: trabajo } \\
\text { colaborativo de los estudiantes; compromiso } \\
\text { ético de los estudiantes; articulación de } \\
\text { actividades de acuerdo a los problemas del } \\
\text { contexto; evaluación por medio de niveles } \\
\text { de dominio; se privilegian el énfasis en los } \\
\text { estudiantes y la metacognición. }\end{array}$ \\
\hline
\end{tabular}

Fuente: elaboración propia 
Anexo 2

Estructura y contenido del cuestionario

\begin{tabular}{|c|c|c|c|}
\hline Variable compleja & Categoría & Variable simple & Nomenclatura \\
\hline \multirow[t]{7}{*}{ I. Signalíticas } & \multirow[t]{7}{*}{ Datos generales } & 1. Contexto (1. Urbano 2. Semiurbano 3. Rural) & 11 \\
\hline & & 2. Antigüedad (1. 0 a 8. 2.9 a 19. 3.20 o más) & 12 \\
\hline & & $\begin{array}{l}\text { 3. Formación (1. Normal Básica. 2. Normal con } \\
\text { Licenciatura. 3. Normal Superior. 4. Licenciatura en } \\
\text { Educación. 5. Licenciatura no en Educación) }\end{array}$ & 13 \\
\hline & & $\begin{array}{l}\text { 4. Posgrado (1. Especialidad. 2. Maestría. 3. Doctorado. } \\
\text { 4. Posdoctorado) }\end{array}$ & 14 \\
\hline & & $\begin{array}{l}\text { 5. Edad (1. Menos de 20. 2. } 20 \text { a 29. } 3.30 \text { a 39. } 4.40 \text { a } \\
\text { 49. 5. } 50 \text { a 59. } 6.60 \text { o más) }\end{array}$ & 15 \\
\hline & & 6. Sexo (1. Masculino. 2. Femenino) & 16 \\
\hline & & $\begin{array}{l}\text { 7. Carga horaria (1. } 12 \text { o menos. 2. } 13 \text { a 20. } 3.21 \text { a 30. } 4 \text {. } \\
\text { Más de } 30 \text { ) }\end{array}$ & 17 \\
\hline \multirow{11}{*}{$\begin{array}{l}\text { II. Finalidades de la } \\
\text { planeación didáctica }\end{array}$} & & \multicolumn{2}{|l|}{ Elabora la planeación } \\
\hline & \multirow[t]{3}{*}{ Normativa } & 1. Por exigencia de los directivos & A1 \\
\hline & & 4. Por necesidad laboral & A4 \\
\hline & & 7. Por requisito administrativo & A7 \\
\hline & Evaluativa & 3. Para evaluación del desempeño & A3 \\
\hline & \multirow[t]{6}{*}{ Pedagógica } & 2. Para organizar mejor el trabajo & A2 \\
\hline & & 5. Para mejorar indicadores educativos & A5 \\
\hline & & 6. Para mejorar el desempeño de los alumnos & A6 \\
\hline & & 8. Para dosificar contenidos & A8 \\
\hline & & 9. Para el desarrollo de competencias en los alumnos & A9 \\
\hline & & 10. Para que los estudiantes aprendan contenidos & A10 \\
\hline \multirow{6}{*}{$\begin{array}{l}\text { III. Enfoque de la } \\
\text { planeación didáctica }\end{array}$} & & Realiza la planeación & \\
\hline & \multirow[t]{3}{*}{ Tradicional } & 11. En torno a los contenidos del programa & B11 \\
\hline & & 12. Basado en los libros de texto & $\mathrm{B} 12$ \\
\hline & & $\begin{array}{l}\text { 15. Con sustento en contenidos diversos con } \\
\text { independencia del programa }\end{array}$ & B15 \\
\hline & \multirow{2}{*}{$\begin{array}{l}\text { Vigente y } \\
\text { socioformativo }\end{array}$} & 13. En función de los aprendizajes esperados & B13 \\
\hline & & $\begin{array}{l}\text { 14. En función de las competencias que deben desarrollar } \\
\text { los estudiantes }\end{array}$ & B14 \\
\hline
\end{tabular}




\begin{tabular}{|c|c|c|c|}
\hline Variable compleja & Categoría & Variable simple & Nomenclatura \\
\hline \multirow{18}{*}{$\begin{array}{l}\text { IV. Aspectos de la } \\
\text { planeación didáctica }\end{array}$} & & En la planeación, en qué medida... & \\
\hline & \multirow[t]{4}{*}{ Aspectos básicos } & 16. Considera a los estudiantes con necesidades especiales & C16 \\
\hline & & $\begin{array}{l}\text { 17. Considera la diversidad de estilos y ritmos de } \\
\text { aprendizaje de los estudiantes }\end{array}$ & $\mathrm{C} 17$ \\
\hline & & $\begin{array}{l}\text { 19. Considera el diseño y elaboración de instrumentos } \\
\text { para evaluar }\end{array}$ & C19 \\
\hline & & $\begin{array}{l}\text { 24. Realiza adecuaciones curriculares para estudiantes } \\
\text { con dificultades para el aprendizaje }\end{array}$ & C24 \\
\hline & \multirow{5}{*}{$\begin{array}{l}\text { Aspectos de } \\
\text { argumentación }\end{array}$} & 20. Explica las estrategias de intervención docente & $\mathrm{C} 20$ \\
\hline & & $\begin{array}{l}\text { 21. Explica y argumenta las estrategias de } \\
\text { intervención docente }\end{array}$ & $\mathrm{C} 21$ \\
\hline & & $\begin{array}{l}\text { 22. Explica las estrategias e instrumentos de evaluación } \\
\text { que pretende utilizar }\end{array}$ & $\mathrm{C} 22$ \\
\hline & & $\begin{array}{l}\text { 23. Explica y argumenta las estrategias e instrumentos } \\
\text { de evaluación que pretende utilizar }\end{array}$ & $\mathrm{C} 23$ \\
\hline & & $\begin{array}{l}\text { 26. Privilegia el énfasis en el trabajo de los estudiantes y } \\
\text { propone la mediación docente }\end{array}$ & C26 \\
\hline & \multirow[t]{8}{*}{$\begin{array}{l}\text { Aspectos } \\
\text { socioformativos }\end{array}$} & $\begin{array}{l}\text { 18. Considera la definición de criterios y estrategias de } \\
\text { evaluación acorde con las competencias a desarrollar }\end{array}$ & $\mathrm{C} 18$ \\
\hline & & $\begin{array}{l}\text { 25. Integra la articulación de actividades en torno a } \\
\text { los problemas o situaciones específicas y relevantes } \\
\text { del contexto }\end{array}$ & $\mathrm{C} 25$ \\
\hline & & $\begin{array}{l}\text { 27. Considera la formación del compromiso ético de } \\
\text { los estudiantes }\end{array}$ & $\mathrm{C} 27$ \\
\hline & & $\begin{array}{l}\text { 28. Plantea situaciones que demandan la colaboración } \\
\text { entre los estudiantes }\end{array}$ & $\mathrm{C} 28$ \\
\hline & & $\begin{array}{l}\text { 29. Considera la evaluación por medio de niveles de } \\
\text { dominio en matrices o rúbricas }\end{array}$ & C29 \\
\hline & & $\begin{array}{l}\text { 30. Toma en cuenta el proceso metacognitivo (plantea } \\
\text { sugerencias para tal fin) }\end{array}$ & C30 \\
\hline & & 31. La considera una carga laboral & C31 \\
\hline & & 32. Recibe apoyo y asesoría para su elaboración & C32 \\
\hline
\end{tabular}

Fuente: elaboración propia 